\title{
ADAPTATION OF THE ROTOR TIME CONSTANT OF INDUCTION MACHINES WITH FIELD ORIENTED CONTROL
}

\author{
S. REHAHLA* and Kh. DERAFA**
}

\begin{abstract}
Procedures for on-line adaptation of rotor time constant are allways based on error models considering two or more machine parameters. A mismatch betwen the parameters in the models and in the machine has strong influence on the adaptation quality and therefore on the result of field oriented control method. The parameter sensitivity of the adaptation method is analysed theoretically and investigated by means of simulation studies. A new approche to improve the parameter robustness by using a reactive power method. is shown.
\end{abstract}

\section{KEY WORDS}

Induction motor_Field oriented control _ On-line adaptation procedure_ Sensitivity

\section{NOMENCLATURE}

d-q: suffixes denoting axes rotating synchronously with supply frequency.

$F$ : coefficient of friction.

$\mathrm{J}$ : rotor inertia

Lr, Ls : apparent self inductance per phase of rotor and stator, respectively

$M$ : apparent mutual inductance

$\mathrm{P}$ : differential operator $\mathrm{d} / \mathrm{dt}$ (or Laplace operator).

$p$ : number of pole pairs

$r, s$ : suffixes denoting rotor and stator, respectively

$\mathrm{Rr}$, Rs : résistance of rotor and stator coils per phase

Te : Electromagnetic torque

$T_{L}$ : laod torque

$\mathrm{Tr}$ : rotor time constant ( $\mathrm{Tr}=\mathrm{Lr} / \mathrm{Rr})$.

$\alpha-\beta$ : suffixes denoting stator-fixed axes

$\theta_{\mathrm{s}}:$ stator electrical angle

$\sigma$ : leakage factor $\left(1-M^{2} / L_{s} L_{r}\right)$.

$\Omega_{\mathrm{r}}$ : mechanical speed.

$\omega_{\mathrm{r}}$ : rotor electrical frequency

$\omega_{\mathrm{s}}:$ stator electrical frequency

$\omega_{\text {sl }}:$ slip frequency.

$\psi:$ flux

* Dir. Labo. Power Electronics, EMP, Bordj-El-Bahri, Algiers, Algeria. Fax.+2132 816097

** Post-graduate Student, EMP, BP17, Bordj-El-Bahri, Algiers, Algeria. Fax.+2132863204 


\section{INTRODUCTION}

The priciple of field oriented control, first established by Blaschke [1], has become one of the most frequently applied control techniques for high performance induction motor drives. It offers the possibility of a decoupled control of torque and rotor flux linkage immediately by their corresponding current components. However, the direct proportionality betwen torque current and motor torque can be guaranteed only if the rotor flux is known and the slip is computed correctly. With the presumption that the rotor flux is not measured directly, the fulfilment of both conditions requires the knowledge of the rotor time contant $\mathrm{Tr}$, and therefore of rotor inductance and rotor resistance. While the nonlinear dependency of the rotor inductance on the magnetising current can be considered by a feed forward compensation, the non predictable dependency of rotor resistance on temperature changes requires the implementation of an on-line adaptation for high performence drive.

Many solutions have been pubished in the last few years [2]. The best changes for a pratical realisation can be awarded to procedures which are easy to implement without additional hardware components (sensors, coils), use terminal currents and voltages as inputs only. Such methods are often based on the calculation of an error signal as equivalent to the rotor resistance detuning driving a readjusting controller for $\mathrm{Tr}$ or the rotor resistance, respectively.

In principle, the error equation contains at least two machine parameters, for instance, stator resistance, leakage inductance or stator inductance. Hence, accuracy and stability of the $\mathrm{Tr}$ adaptation are essentially influenced by the accuracy of the knowledge of these parameters and their working point dependencies (main and leakage field saturation, temperature).

\section{MATHEMATICAL MODEL OF THE INDUCTION MOTOR}

The basic equation of induction machine in the $d-q$ axis which synchronously rotates with an angular velocity $\omega_{\mathrm{s}}$ are expressed as follows :

\subsection{Electrical Equations}

$$
\begin{aligned}
& {\left[\begin{array}{l}
V_{q s} \\
V_{d s}
\end{array}\right]=\left[\begin{array}{cc}
R_{s} & 0 \\
0 & R_{s}
\end{array}\right]\left[\begin{array}{l}
i_{q s} \\
i_{d s}
\end{array}\right]+\frac{d}{d t}\left[\begin{array}{l}
\Psi_{q s} \\
\Psi_{d s}
\end{array}\right]+\left[\begin{array}{cc}
0 & \omega_{s} \\
-\omega_{s} & 0
\end{array}\right]\left[\begin{array}{l}
\Psi_{q s} \\
\Psi_{d s}
\end{array}\right]} \\
& {\left[\begin{array}{l}
0 \\
0
\end{array}\right]=\left[\begin{array}{cc}
R_{r} & 0 \\
0 & R_{r}
\end{array}\right]\left[\begin{array}{l}
i_{q r} \\
i_{d r}
\end{array}\right]+\frac{d}{d t}\left[\begin{array}{l}
\Psi_{q} \\
\Psi_{d r}^{r}
\end{array}\right]+\left[\begin{array}{cc}
0 & \omega_{s l} \\
-\omega_{s l} & 0
\end{array}\right]\left[\begin{array}{l}
\Psi_{q r} \\
\Psi_{d r}
\end{array}\right]}
\end{aligned}
$$

with: $\omega_{\mathrm{sl}}=\omega_{\mathrm{s}}-\mathrm{p} \Omega_{\mathrm{r}}$

Considering the rotor flux $\left(\psi_{\mathrm{dr}}, \psi_{\mathrm{qr}}\right)$, the mechanical speed $\left(\Omega_{\mathrm{r}}\right)$ as state variables, the stator currents $\left(i_{d s}, i_{q s}\right)$, the slip frequency $\left(\omega_{s l}\right)$ as control variables and the load torque as disturbance [3] we obtain the equations (2), (3) and (4). 


\subsection{Field Equations}

The flux linkage vectors are related to the stator and rotor currents by the following relationship [4]:

$$
\begin{aligned}
& \Psi_{\mathrm{ds}}=\mathbf{L}_{\mathrm{s}} \mathbf{i}_{\mathrm{ds}}+\mathbf{M i} \mathbf{i}_{\mathrm{dr}} \\
& \Psi_{\mathrm{qs}}=\mathbf{L}_{\mathrm{s}} \mathbf{i}_{\mathrm{qs}}+\mathbf{M i} \mathbf{q}_{\mathrm{qr}} \\
& \Psi_{\mathrm{qr}}=\mathbf{L}_{\mathrm{r}} \mathbf{i}_{\mathrm{qr}}+\mathbf{M} \mathbf{i}_{\mathrm{qs}} \\
& \Psi_{\mathrm{dr}}=\mathbf{L}_{\mathrm{r}} \mathbf{i}_{\mathrm{dr}}+\mathbf{M} \mathbf{i}_{\mathrm{ds}}
\end{aligned}
$$

In practice, rotor currents are inaccessible quantities in a squerrel cage motor. Therefore, the rotor current in equation (2) is eliminated by the corresponding flux vector and stator current vector.

$$
\frac{d}{d t}\left[\begin{array}{l}
\Psi_{d r} \\
\Psi_{q r}
\end{array}\right]=\left[\begin{array}{cc}
-\frac{1}{\mathbf{T}_{\mathbf{r}}} & \omega_{\mathrm{sl}} \\
-\omega_{\mathrm{sl}} & -\frac{1}{\mathbf{T}_{\mathbf{r}}}
\end{array}\right] \cdot\left[\begin{array}{l}
\Psi_{\mathrm{dr}} \\
\Psi_{\mathbf{q r}}
\end{array}\right]+\left[\begin{array}{cc}
\frac{M}{T_{r}} & 0 \\
0 & \frac{M}{T_{r}}
\end{array}\right] \cdot\left[\begin{array}{l}
i_{d s} \\
i_{q s}
\end{array}\right]
$$

\subsection{Mechanical Equation}

$$
\begin{aligned}
& T_{e}-T_{L}=J \frac{d \Omega_{r}}{d t}+F \Omega_{r} \\
& \text { with }: T_{e}=\frac{3 p M}{2 L_{r}}\left(\Psi_{d r} i_{q s}-\Psi_{q r} \quad i_{d s}\right)
\end{aligned}
$$

From the equations (3), (4) we establish the following machine model fed by current:

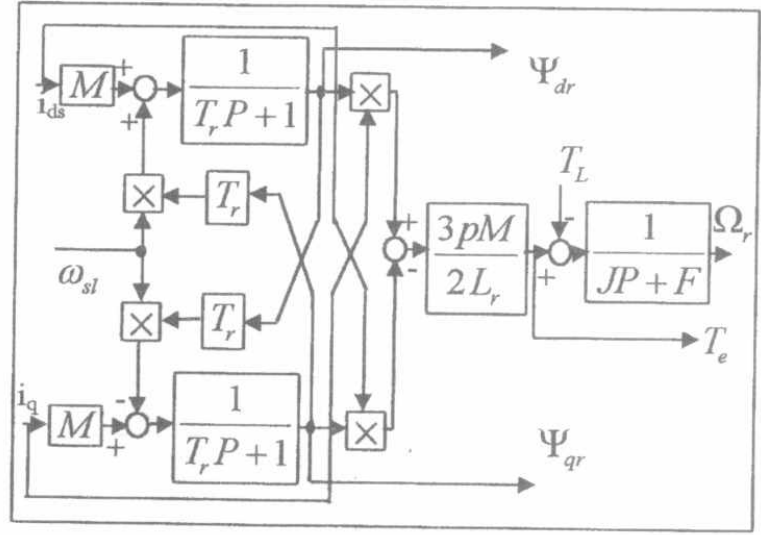

Fig.1 Induction machine model 


\section{FIELD ORIENTATION}

The flux models contain field coordinates (i.e. d-q quantities) that are dc quantities in the steady state. This greatly simplifies the control approach when dc quantities are dealt with. Also, it is expedient to allign the rotor flux $\left(\psi_{r}\right)$, along the d-axis, we obtain:

$$
\Psi_{\mathrm{dr}}=\Psi_{\mathrm{r}} ; \Psi_{\mathrm{qr}}=0
$$

\subsection{Machine Model with Rotor Flux Orientation}

Substituting the flux equation (5) into equations (2), (3) and (4) and considering the stator currents $\left(i_{d s}, i_{q s}\right)$ as control input: the machine flux model can be formulated as following

$$
\begin{aligned}
& \mathbf{T}_{\mathbf{r}} \frac{\mathrm{d} \Psi_{\mathrm{r}}}{\mathrm{dt}}+\Psi_{\mathrm{r}}=\mathbf{M i}_{\mathrm{ds}} \\
& \omega_{\mathrm{sl}}=\frac{\mathbf{M i}_{\mathrm{qs}}}{\mathbf{T}_{\mathbf{r}} \Psi_{\mathrm{r}}} \\
& \mathbf{T}_{\mathrm{e}}=\frac{3 \mathbf{p} \mathbf{M}_{2}}{2 \mathbf{L}_{\mathrm{r}}} \Psi_{\mathrm{r}} \mathrm{i}_{\mathrm{qs}}
\end{aligned}
$$

\subsection{Structure Control of the Rotor Flux Model}

Considering the rotor flux $\left(\psi r^{*}\right)$ and the torque $\left(T e^{\star}\right)$ as reference control, the equations system (6) gives the structure (fig. 2 ) with the following relationship:

$$
\begin{aligned}
& \frac{1}{\mathbf{M}}\left(\mathbf{T}_{\mathrm{r}} \frac{\mathbf{d} \Psi_{\mathrm{r}}^{*}}{\mathbf{d t}}+\Psi_{\mathrm{r}}\right)=\mathbf{i}_{\mathrm{ds}} \\
& \omega_{\mathrm{sl}}=\frac{\mathbf{M i}_{\mathbf{q s}^{\mathrm{s}}}}{\mathbf{T}_{\mathrm{r}} \Psi^{*}{ }_{\mathrm{r}}} \\
& \frac{2 \mathbf{L}_{\mathrm{r}} \mathbf{T}^{*}{ }_{\mathrm{e}}}{3 \mathrm{MM} \Psi^{*}{ }_{\mathrm{r}}}=\mathbf{i}_{\mathrm{qs}}
\end{aligned}
$$

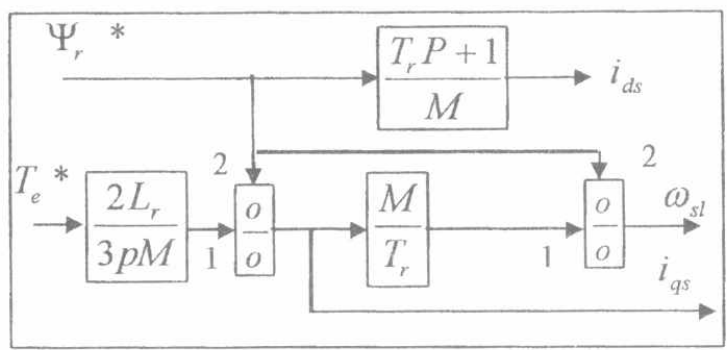

Fig. 2 :Field oriented control structure (FOC) 


\section{SPEED CONTROL}

The speed is controlled with a classical $(\mathrm{PI})$ controller that generates the reference torque $\left(\mathrm{T}_{\mathrm{e}}^{*}\right)$ to be applied to the open loop structure (FOC).

The rotor flux reference $\left(\psi r^{*}\right)$ estimated from the nominal voltage and frequency values of the machine, is controlled simply by the block "flux function", which is defined by the following relationship:

$$
\Psi_{r}^{*}=\left\{\begin{array}{l}
\Psi_{r 0} \text { if }\left|\Omega_{r}\right| \leq \Omega_{r 0} \\
\frac{\Psi_{r 0} \cdot \Omega_{r 0}}{\left|\Omega_{r}\right|} \text { if } \mid \Omega_{r} p \Omega_{r 0}
\end{array}\right.
$$

The rotor flux reference $\left(\psi r^{*}\right)$ is constant in the constant-torque region, but it is weakened as inversely proportional to speed in the constant-power region [4].

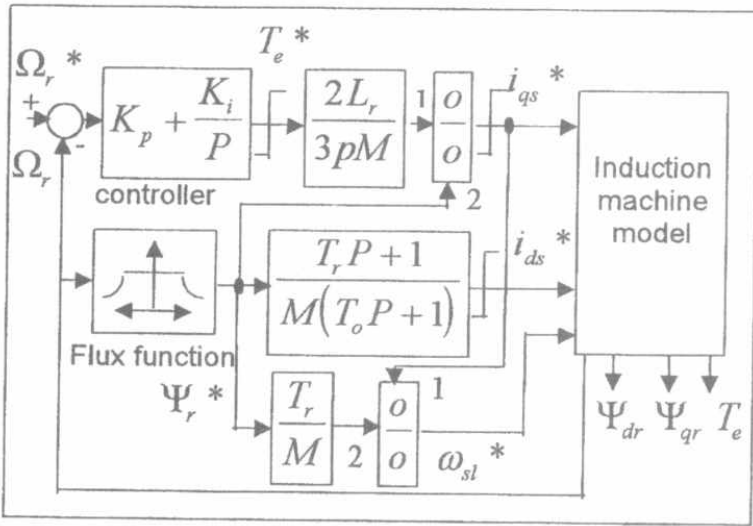

Fig.3. Speed control structure with rotor flux orientation

\section{ADAPTATION PROCEDURE}

\subsection{Stationary Frame Model}

The dynamic machine model in the stationary reference frame in $\alpha-\beta$ notation is shown in fig. 4 , where $L_{T H}$ is the equivalent leakage inductance of the stator and rotor transferred to the input [4].

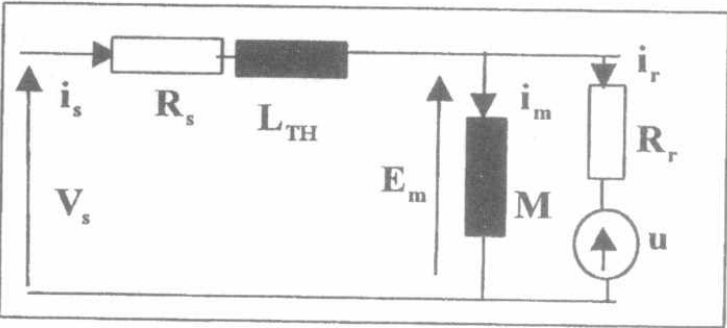

Fig.4 : Equivalent circuit of the induction machine 
The emf can be derived immedately from fig. 4 as:

$$
E_{\mathrm{m}}=\mathbf{V}_{\mathrm{s}}-\mathbf{R}_{\mathrm{s}} \mathbf{i}_{\mathrm{s}}-\left(\mathrm{L}_{\mathrm{TH}}\right) \frac{\mathbf{d i}_{\mathrm{s}}}{\mathrm{dt}}
$$

The reactive power is given by

$$
\mathbf{Q}_{\mathrm{m}}=\mathbf{E}_{\mathrm{m} \beta} \mathbf{i}_{\mathrm{s} \alpha}-\mathbf{E}_{\mathrm{m} \alpha} \mathbf{i}_{\mathrm{s} \beta}
$$

The reactive power is consumed only in the main inductance Lm then:

$$
\mathbf{Q}_{\mathrm{m}}=\omega_{\mathrm{s}} \mathbf{M I}_{\mathrm{m}}^{2}
$$

The stored energy $\mathrm{Fm}$ in the main inductance may be formulated as following [5]

$$
\begin{aligned}
& \mathbf{F}_{\mathrm{m}}=\frac{\mathbf{Q}_{\mathrm{m}}}{\omega_{\mathrm{s}}}=\frac{\left(\mathbf{i}_{\mathrm{s} \alpha} \mathbf{E}_{\mathrm{m} \beta}-\mathbf{i}_{\mathrm{s} \beta} \mathbf{E}_{\mathrm{m} \alpha}\right)}{\omega_{\mathrm{r}}+\frac{1}{\mathbf{T}_{\mathrm{r}}} \frac{\mathbf{i}_{\mathrm{qs}}^{*}}{i_{\mathrm{ds}}^{*}}} \\
& \mathbf{F}_{\mathrm{m}}^{*}=\frac{\mathbf{Q}_{\mathrm{m}}^{*}}{\omega_{\mathrm{s}}}=\mathbf{M I}_{\mathrm{m}}^{* 2}
\end{aligned}
$$

Substituting equation (9) in (12) yelds

$$
F_{m}=\frac{\left|i_{s \alpha} V_{s \beta}-L_{T H} i_{s \alpha} \frac{d i_{s \beta}}{d t}-i_{s \beta} V_{s \alpha}+L_{T H} i_{s \beta} \frac{d i_{s \alpha}}{d t}\right|}{\omega_{r}+\frac{1}{T_{r}} \frac{i_{q s}^{*}}{i_{d s}^{*}}}
$$

$I_{m}^{*}$ : magnetisation current without load, it is initialy measured on $50 \mathrm{~Hz}$, under nominal voltage.

\subsection{Application}

The block diagram of the considered field oriented control system is shown in fig. 5 . Reference values are marked with a superscript. The special configuration of the current controller is not of interest for the studies proposed in this paper; only it must be able to fulfil the condition $i_{q s}=i_{q s}^{*}, i_{d s}=i^{*}$ ds in steady state. 


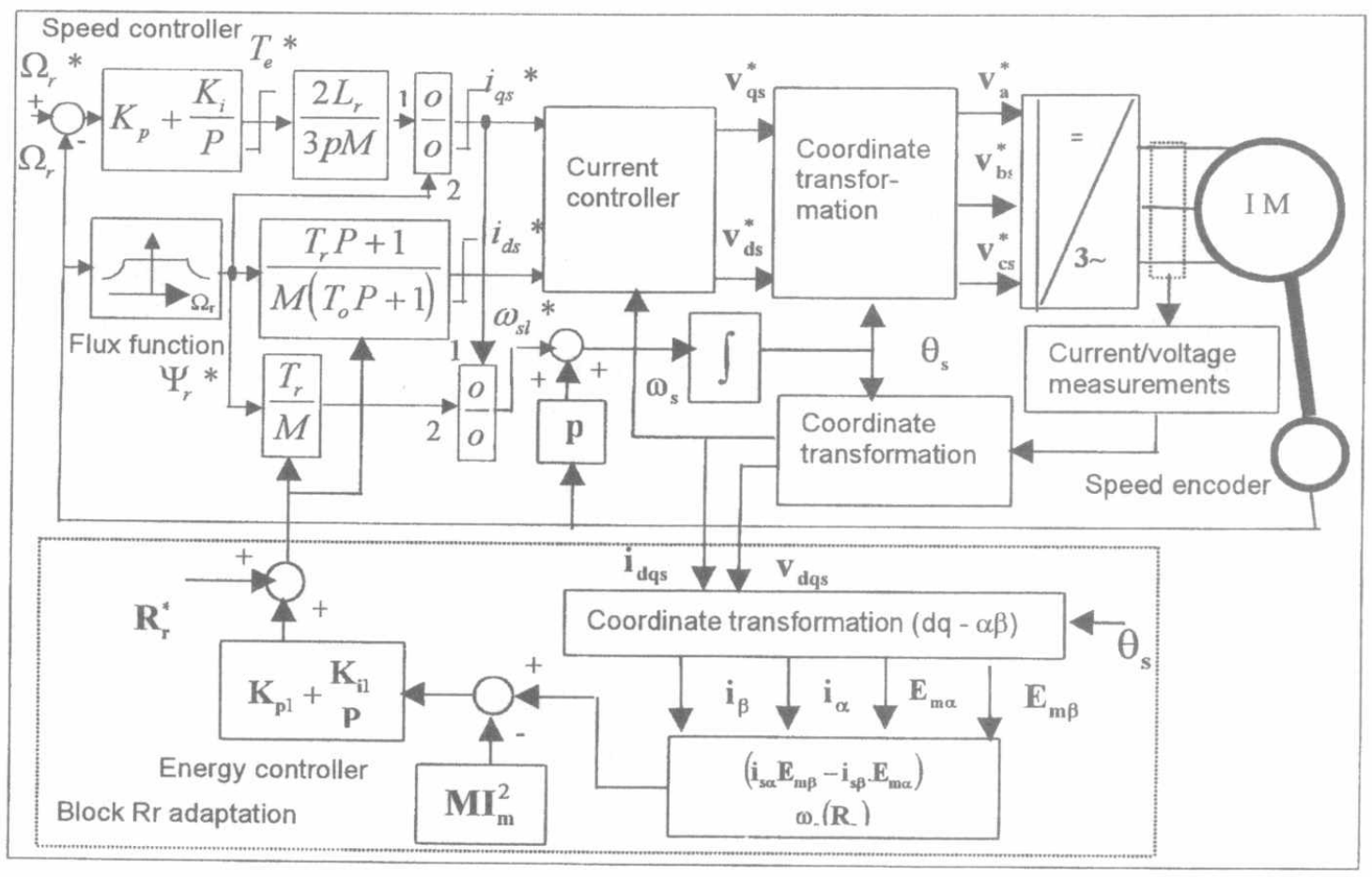

Fig.5. Field oriented control system with rotor resistance adaptation

The error of the speed control loop generates the reference torque $\left(\mathrm{Te}^{\star}\right)$ through a $\mathrm{PI}$ controller and limiter, obtained with an analytical method [6], which is divided by the flux $\left(\psi r^{*}\right)$ to generate the command current ( $\left.i_{q s}^{*}\right)$ (equation 7 ).

A step change in command flux or torque will cause the generation of $\sigma$ function (due to $P \Psi_{r}^{*}$ in Fig.5). In practice, the rate of rise of machine currents are limited by the stator leakage inductance, therefore a very small first order time delay is incorporated in the flux input path to ensure a smooth function of ids* with a pole location of $-1 / \mathrm{T} 0$.

The P.I parameters of the energy controllers are obtained by Ziegler and Nichols méthod [7].

The equation (14) which includes the rotor resistance $\mathrm{Rr}$ gives the tunning model. The equation (13) gives the reference model. In both models all parameters are influenced by the saturation effects in the machine.

However the used adaptation procedure is to cancel the error signal between the reference model and the tunning model by minimizing the saturation effects; so in the block $\mathrm{Rr}$ adaptation (Fig.5): the starting-point for the power balance method is the reactive power (equation 14).

The vector rotator angle $\theta$ s which is influenced by the actualised rotor time constant $(\mathrm{Tr})$ is defined by :

$$
\theta_{s}=\int\left(\omega_{s l}+p \Omega_{r}\right) d t
$$

The inverter being used is a three-phase bridge employing I.G.B.T. transistors. 
The instantaneous inverter current/votage arefed back to perform the current control and the adaptation procedure used

\section{SIMULATION RESULTS}

To verify analitycal key results and the validity of the proposed control scheme, the aforementioned structure of field oriented control system with rotor resistance adaptation was tested by simulation on pentium personal computer. Computer simulation was carried out using Matlab environment.

The fig. 6 shows the simulated results under a nominal torque and a rotor flux $\left(\psi r^{*}\right)$ of $1 \mathrm{~Wb}$. At the moment $t 1$ (2 sec, fig. $\left.6-b\right)$ we put a linear variation of $+50 \%$ betwen the rotor resistance used in machine model and the rotor resistance $(T r=L r / R r)$ used in the speed control structure (fig.3): consequence the $\psi_{\mathrm{qr}}$ is not equal to zero (fig.6-e) and $\psi_{r}$ comes different of the reference value $\left(\psi r^{*}=1 \mathrm{~Wb}\right.$.) fig.6d), the electromagnetic torque Te decrease lightly (fig.6-g), therefore the decoupling control is not effective on ' $d$ axis'. At the moment $t 2$ (3.5 sec., fig.6-b) we introduce the adaptation procedure proposed and the parameters ( $\psi_{\mathrm{qr}}, \psi_{\mathrm{dr}}, \psi_{\mathrm{r}}$ and Te) come to theirs initial values, so the decoupling or oriented control is now effective.

The speed response $\Omega r$. (fig.6-a), is not affected by the dynamic of the decoupling control, due to its controller.

\section{CONCLUSION}

It has been shown that the accuracy of the motor parameters in the rotor time contant adaptation error model has an important effect on the adaptation accuracy and therefore the quality of the field orientation. Relatively small deviations can already result in instability of the control system. Hence the paramater sensitivity becomes an important criterion for the choice of an adaptation procedure for application.

Simulation studies are necessary because an analytical analysis does not yield statments of the stability of the problem.

The reactive power method turns out to yield the best results independent of stator resistance deviations and with an acceptable sensitivity to the inductances.

\section{MACHINE PARAMETERS}

$P n=1(k W), U n=220 / 380(V), N n=2830(r p m), f=50(\mathrm{~Hz}) \operatorname{Iny}=2.7(A), \operatorname{In} \nabla=4.7(A)$, $p=1, R s=5.06(\Omega), R r=3.1(\Omega), L s=0.386=L r, M=0.374(H), \quad F=0.0011(\mathrm{Nm} / \mathrm{rad} / \mathrm{s})$,

$\mathrm{J}=0.006\left(\mathrm{~kg} \cdot \mathrm{m}^{2}\right), \quad \mathrm{I}^{\star} \mathrm{m}=3.12(\mathrm{~A})$,

$\mathrm{Kp}=4^{\star} 2 \mathrm{~J} / \mathrm{Tr}, \mathrm{Ki}=\mathrm{J}^{\star} \omega_{0}{ }^{2}, \mathrm{TO}=0.025(\mathrm{sec}), \omega_{0}{ }^{2}=\omega_{\mathrm{sl}}{ }^{2}+1 / \mathrm{Tr}, \mathrm{kp} 1=0.0012, \quad \mathrm{ki} 1=0.00012$. 


\begin{tabular}{|l|l|}
\hline EP-1 & 9 \\
\hline
\end{tabular}

\section{REFERENCES}

[1] F. Blaschke: "The principle of field orientation as applied to the new transvector closed loop control system for rotating field machines", Siemens review, Vol 34, may 1972, pp 217-220.

[2] Rowan T.M., Kerkman R.J. and Leggate D.

"A simple on line adaptation for indirect field orientation of an induction machine", I.E.E.E. Trans., 1991, IA-27, (4), pp. 720-726

[3] Young-Dong-Li: "Etude comparative des lois de commande des MAS alimentées par onduleur de tension MLI: Réalisation d'une commande numérique de positionnement", thèse de doctorat à I'INP, Toulouse France, 1987.

[4] B. K. Bose: "Power electronics and AC drives",

Prentice - hall, Englewood Cliffs, New Jersey 07632. 1986

[5] A. Faidellah: "Contribution à l'identification et la commande vectorielle des machines asynchrones", thèse de doctorat à I'INPL, Nancy France, 1995.

[6] S. Rehahla: "Structure de commande en courant par orientation du flux rotorique d'une machine asynchrone triphasée", Proceedings IEEA, Conférence Internationale Batna, Vol. No:1 Janv. 1997, Algérie.

[7] P. de Larminat et Y. Thomas: "Automatique des systèmes linéaires", Tome 3, Commande, Editions flammarion sciences 20, rue de vaugirard-Paris-6 1977. 
$\Omega_{\mathrm{r}}(\mathrm{rad} / \mathrm{sec})$.

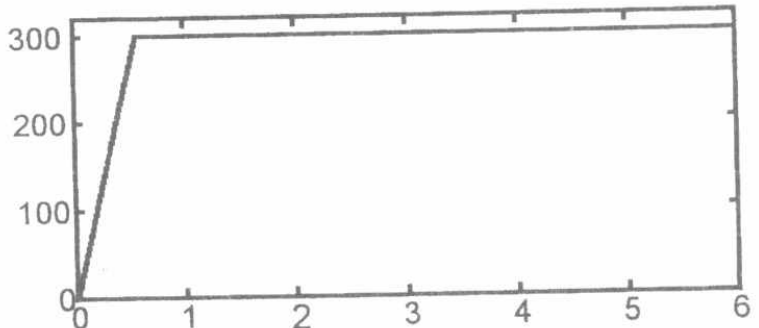

(a)

$\mathrm{R}_{\mathrm{r}}(\Omega)$

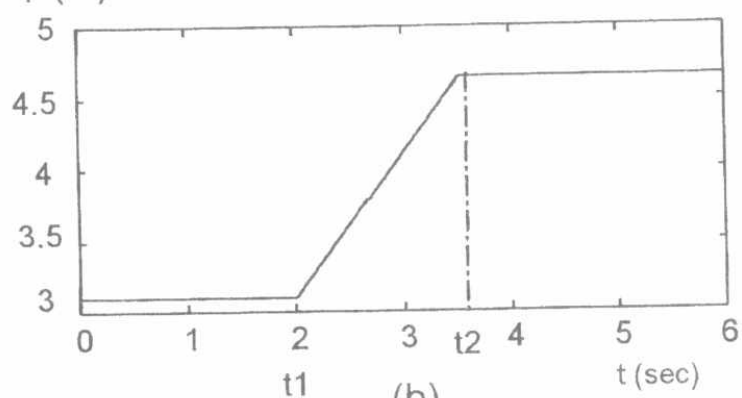

(b)

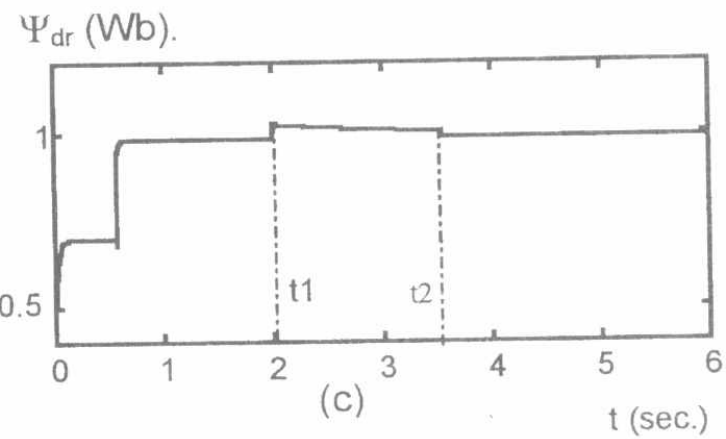

$\Psi_{\mathrm{r}}(\mathrm{Wb})$.

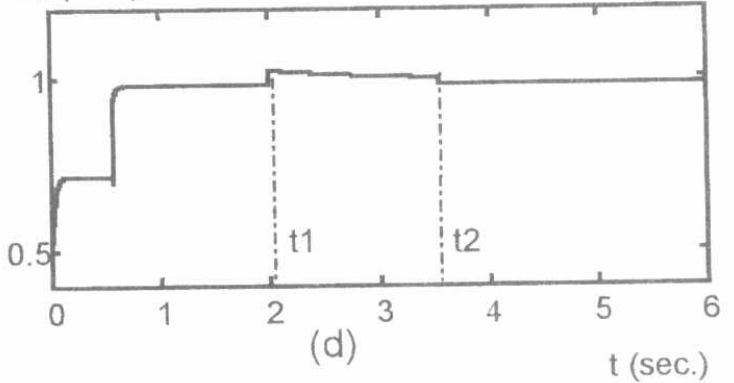

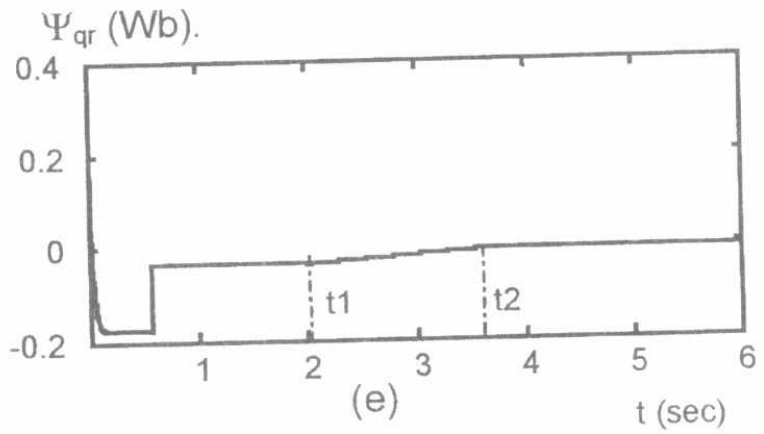

$\mathrm{T}_{\mathrm{e}}(\mathrm{N}-\mathrm{m})$.

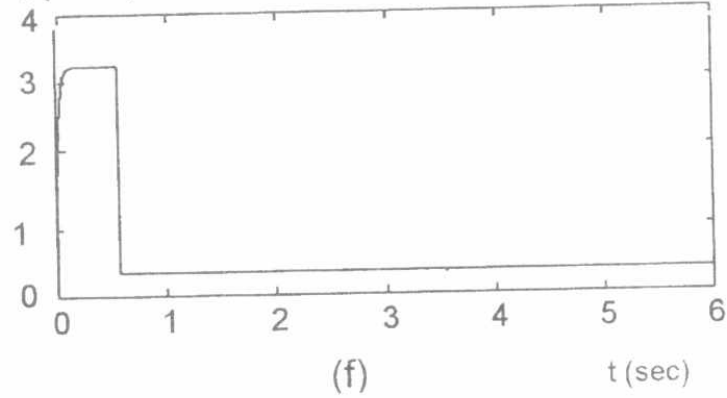

$\mathrm{T}_{\mathrm{e}}(\mathrm{N}-\mathrm{m})$.

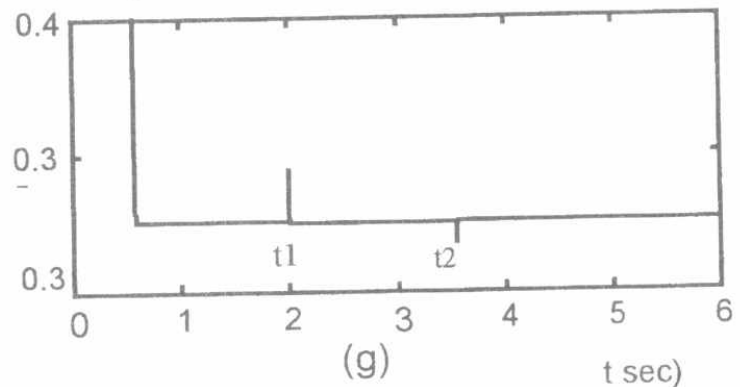

Fig.6. Simulation results of the field oriented control system with rotor resistance adaptation. (a) Speed response $\Omega_{\mathrm{r}}$. (b) Rotor resistance $\left(R_{r}\right)$ variation. (c) Flux component: $\Psi_{\text {dr }}$. (d) Flux response $\Psi_{r}$. (e) Flux component

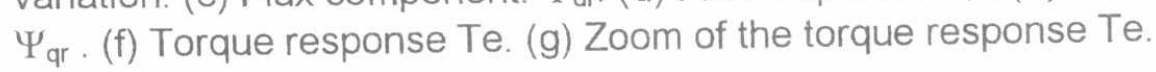

